\title{
Effects of Elevated Diluent Contents on the Combustion and Emissions of Biogas-Diesel RCCI Engine at Full Load
}

\author{
Ibrahim B. Dalha ${ }^{\# * 1}$, Mior A. Said ${ }^{\# 2}$, Zainal A. Abdul Karim³ \\ ${ }^{*}$ Centre for Automotive Research and Electric Mobility (CAREM), \\ Universiti Teknologi PETRONAS, Bandar Seri Iskandar 32610, Perak, Malaysia \\ 1 ibrahim_16005836@utp.edu.my \\ ${ }^{2}$ miorazman@utp.edu.my \\ 3 ambri@utp.edu.my \\ ${ }^{*}$ Faculty of Engineering, Ahmadu Bello University, Samaru 1045, Zaria, Nigeria \\ 11p20420@abu.edu.ng
}

\begin{abstract}
Difficulty in carbon dioxide $\left(\mathrm{CO}_{2}\right)$ removal, coupled with the poor combustion due to diverse constituent of biogas, encouraged an investigation of the influence of high diluent $\left(\mathrm{CO}_{2}, 25-45 \% \mathrm{vol}\right)$ content and biogas fraction $(40-70 \%)$ on the emissions of biogas/diesel dual-fuel reactivity-controlled compression ignition engine. The experiment was conducted at full load and a speed of $1600 \mathrm{rpm}$. The results showed distinct temperature trends for all the $\mathrm{CO}_{2}$ ratios and biogas fractions while radiation absorption effect of high $\mathrm{CO}_{2}$ content inhibits the combustion. Biogas with $35 \% \mathrm{CO}_{2}$ proportion and a fraction of $50 \%$ produced the highest maximum temperature and heat released. The combustion resulted in a lower PPRR minimizing the higher-ringing strength tendency. At a $\mathbf{4 0 \%}$ biogas fraction and $\mathbf{2 5 \%}$ $\mathrm{CO}_{2}$, which simultaneously showed the highest ITE of $38.29 \%$, the lowest BSFC of $7.41 \mathrm{~g} / \mathrm{kWh}$ was achieved. An increase in the biogas fraction indicated a significant decrease in the nitrogen oxides (NOx) and particulate (PM) emissions by approximately 62.66, and $26.59 \%$, respectively. Also, an increase in the diluent $\mathrm{CO}_{2}$ content decrease the carbon monoxide (CO) and unburned hydrocarbon (UHC) emissions by approximately $\mathbf{2 0 . 3 0}$, and $\mathbf{3 8 . 8 3} \%$, respectively. However, an increase in those parameters resulted in a severe UHC and CO emissions trade-off with the NOx and PM emissions, though a $70 \%$ biogas fraction indicated the potentials of reducing the impact of the trade-off.
\end{abstract}

Keywords: RCCI Combustion, Biogas, Fuel Fraction, High Diluent Content, Emissions Trade-off

\section{INTRODUCTION}

An increasing rate of pollutants prompted a more global search for secured energy provision through alternative means [1]. The use of alternative low reactivity fuel (LRF) alongside fossil energy demonstrated a considerable potential to address some challenges of global emissions through the invention of more efficient technologies [2], such as dual-fuel reactivity-controlled compression ignition (RCCI) combustion. RCCI mode involves an in-cylinder blending of two or more fuels of varying reaction rates to enhance the combustion magnitude by stratification [3,4]. According to [5], the measures used to address the nitrogen oxides (NOx) and soot emissions in RCCI resulted in an unacceptable rise in carbon monoxide (CO) and unburned hydrocarbon (UHC) emissions. Among the measures is the use of gaseous fuels, but article [6] reported that natural gas and diesel combustion also produce high CO and UHC emissions. However, the benefit of none gaseous biofuels and natural gas received a due and rigorous examination in RCCI mode with minimal attention allotted to the use of biogas [7,8]. According to [9], the composition of biogas renders it low CO, UHC, and NOx emissions fuel, though unpurified biogas might increase carbon dioxide $\left(\mathrm{CO}_{2}\right)$ emission.

Raw biogas is a fuel obtained through anaerobic digestion of biological compounds, which contained methane $\left(\mathrm{CH}_{4}\right), \mathrm{CO}_{2}$, a small quantity of nitrogen $\left(\mathrm{N}_{2}\right)$ and other impurities [10,11]. The differences in the content of biogas pose various combustion control issues, as in [12], that may likely extend to emissions. Reference [13] investigated the workability of low-grade biogas (5\% $\mathrm{H}_{2}$ (hydrogen), 40\% $\mathrm{CO}, 5 \% \mathrm{CH}_{4}$, and $50 \% \mathrm{~N}_{2}$ ) in RCCI combustion. Achieved, was high ITE and controlled combustion phasing (CA50) because of prime injection timing but, excessive main injection retarded the combustion. High UHC and CO emissions were observed with controlled NOx and soot emissions but, varying the start of diesel injection (SOI) lowered the elevated $\mathrm{CO}$ emission. Using the same composition, article [14] reported similar attributes and inferred that low temperature in the cylinder lowered the soot and NOx emissions. In comparison with the biogas of different composition $\left(15 \% \mathrm{H}_{2}, 30 \% \mathrm{CO}, 5 \% \mathrm{CH}_{4}\right.$, and $\left.50 \% \mathrm{~N}_{2}\right)$, article [15] stated that an increase in the exhaust gas recirculation (EGR) resulted in reduced peak pressure and improved CA50, but decreases the ITE for both biogases. The emissions trends remained similar to the reports of [13] and [14]. Recently, article [16] investigated the effects of $\mathrm{H}_{2}$ addition to landfill gas-diesel RCCI combustion. The results indicated delayed 
eruption, reduced engine load and increased peak pressure. The rate of $\mathrm{CH}_{4}$ emission decreased due to increased combustion duration, and $\mathrm{CO}_{2}$ discharge increased due to an increase in the equivalence ratio. Presence of $\mathrm{CO}_{2}$ in the landfill causes reduced NOx and $\mathrm{CO}$ emissions because of the interactive effects of $\mathrm{H}_{2}$ and $\mathrm{CO}$ in the mixture. These attributes signify that the potentiality of biogas in reducing the high UHC and CO emissions may compromise with the composition and strategy used; thus, encouraging an investigation of high $\mathrm{CO}_{2}$ content. Therefore, this paper investigated experimentally, the effects of $\mathrm{CO}_{2}$ portions at various biogas fractions on the emission characteristics of biogas and diesel at full engine load, and speed of 1600rpm in dual-fuel RCCI mode.

\section{Materials AND Methods}

The materials used and the methodology adopted for the research is presented in this section.

\section{A. Measurement and Experimental Settings}

The technical information on the test equipment is presented in Table 1, while Fig 1 depicted the layout of the engine test rig. The research investigated experimentally, the influence of port-injected biogas with high $\mathrm{CO}_{2} / \mathrm{CH}_{4}$ ratio and direct-injected diesel on the emissions attributes of the RCCI engine at full engine capacity. The biogas was port-injected at a maximum distance of $115 \mathrm{~mm}$ from the inlet valve position to ensure sufficient mixing of the biogas and air before entering the cylinder.

The measurement of engine load and speed was achieved using an eddy current dynamometer (DW10, 10kW, $50 \mathrm{Nm}, 13000 \mathrm{rpm}$ ) while a rotary type encoder (E50S8-360-3-T-24) enabled the measurement of crank angle. The cylinder pressure, air pressure, air temperature, and airflow rate were measured using a pressure transducer, pressure sensor (range: $-1-1 \mathrm{bar}$ ), $\mathrm{K}-$ type thermocouple (range: $0-1100^{\circ} \mathrm{C}$ ), and hot-wire flow meter $(0-$ $30 \mathrm{~m} / \mathrm{Sec}$ ), respectively. A weighing scale attached to the engine control unit was used to determine the diesel mass flow rate and volume through the data acquisition system. Also, the biogas pressure was decompressed to 2 bar using a Linde HiQ pressure regulator, and IGO8 R3 Concoa gas flow meter was used to measure its mass flow rate.

TABLE I. The technical information of the engine is used for the test

\begin{tabular}{|l|l|l|}
\hline Description & Specifications & \\
\hline Model & L100V & \\
\hline Type & Single cylinder, 4-stroke, air-cooled engine & \\
\hline Bore/Stroke & $86 / 75 \mathrm{~mm}$ & \\
\hline Displacement & $435 \mathrm{~cm}^{3}$ & \\
\hline Compression ratio & $20.0 \pm 0.3$ & \\
\hline Fuel injection timing & $21^{\circ}$ CA BTDC & \\
\hline Maximum Rated Output & Engine speed & $3600 \mathrm{rpm}$ \\
\hline & Output & $6.8 \mathrm{~kW}$ \\
\hline
\end{tabular}

\section{A. Experimental Procedure}

An experiment was carried out to investigate the emission characteristics of the engine at a speed of $1600 \mathrm{rpm}$, and a load of 6.5 bar indicated mean effective capacity (IMEP) in a conventional premixed port injection of simulated biogas along with the direct injection of neat diesel. Please refer to the article [17] for a detailed understanding of the load measurement method. An advanced injection timing of 21o CA BTDC was considered because early direct injection timing improves the in-cylinder mixing and fuel combustion at low load $[18,19]$. The research aimed at investing the high maximum temperature condition based on the assertion that it might reduce the $\mathrm{CO}$ and $\mathrm{UHC}$ emissions discharge.

The biogas mass was calculated based on the estimated average high reactivity fuel (HRF) injected at full engine load to maintain the fractions of $40 \%, 50 \%, 60 \%$, and $70 \%$, as described in [20,21]. Keeping speed and load constant, biogas fractions of $40-70 \%$ at an interval of $10 \%$ were port-induced for each of the $25 \%, 35 \%$, and $45 \% \mathrm{CO}_{2}$ proportions.

\section{B. Fuels Used}

This research investigated the performance of Euro 2M diesel, obtained from the PETRONAS Research Center (PRC), as direct-injected test fuel in RCCI mode. The study uses low-quality gaseous fuel, as premixed port-induced LRF, which is composed of $25 \%, 35 \%$, and $45 \% \mathrm{CO}_{2}$ by mole with the balance as $\mathrm{CH}_{4}$, to simulate raw biogas fuel. Table 2 presented some properties of the direct-injected fuels and simulated biogas used. 


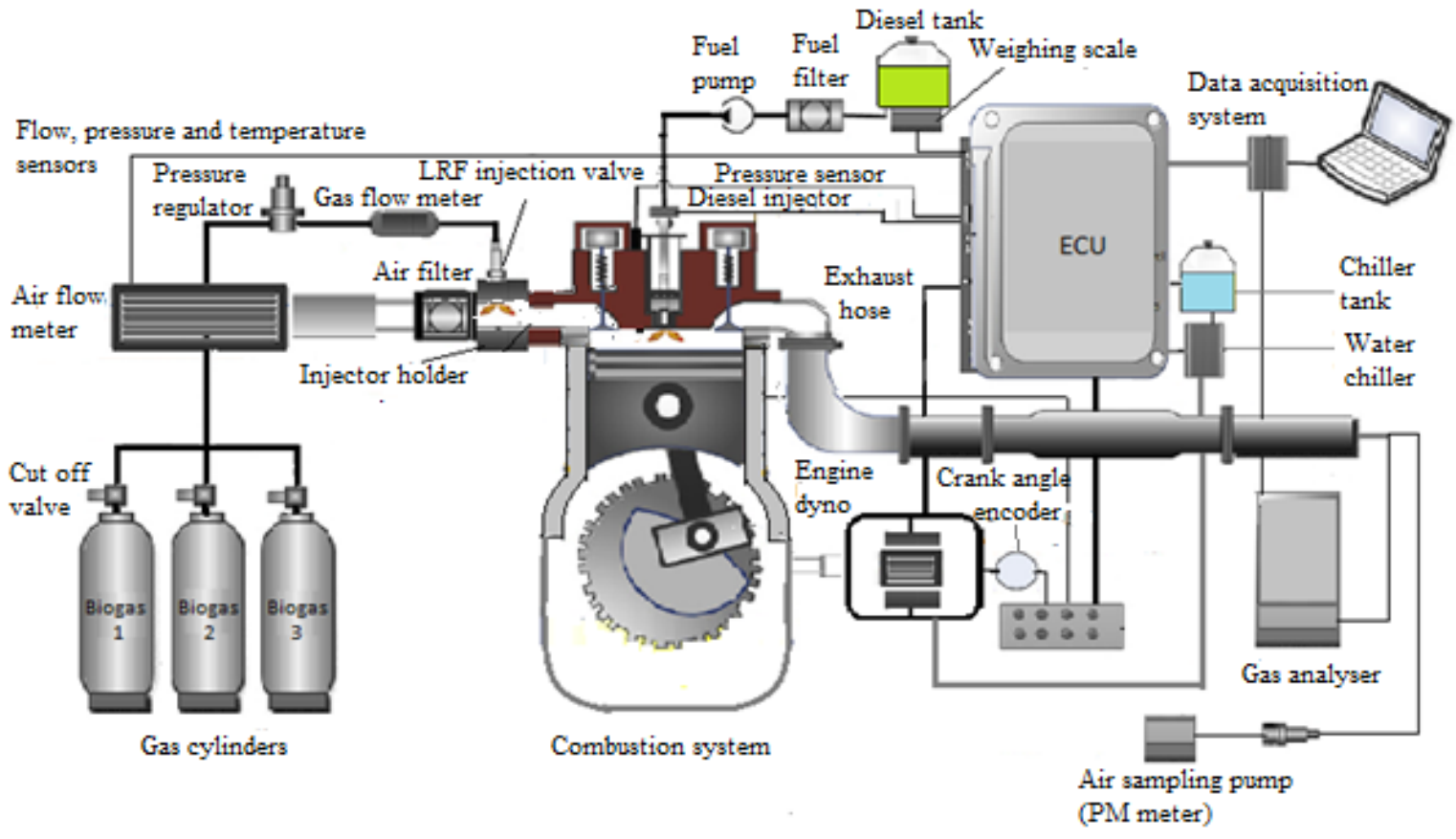

Fig. 1. An illustration of the engine test rig modified from [17]

TABLE 2. Characteristics of the fuels used for the test

\begin{tabular}{|l|l|l|l|l|}
\hline Properties & Biogas 1 & Biogas 2 & Biogas 3 & Diesel \\
\hline Proportion by mole & $25 \% \mathrm{CO}_{2}$ & $35 \% \mathrm{CO}_{2}$ & $45 \% \mathrm{CO}_{2}$ & \\
\hline Density $\left(\mathrm{kg} / \mathrm{m}^{3}\right)$ & 1.353 & 1.563 & 1.772 & $820-832$ \\
\hline Lower flammability limit $(\mathrm{mol} \%)$ & $6.1-22.4$ & $6.9-25.4$ & $8.3-30.3$ & $0.6-7.5$ \\
\hline Molecular weight $(\mathrm{g} / \mathrm{mol})$ & 23.5132 & 25.928 & 28.896 & 168 \\
\hline Specific gravity at $0^{\circ} \mathrm{C}$ & 1.05 & 1.21 & 1.37 & 0.85 \\
\hline Specific volume $\left(\mathrm{m}^{3} / \mathrm{kg}\right)$ & 0.739 & 0.640 & 0.564 & $1.18-1.22$ \\
\hline Kinematic viscosity $(\mathrm{cSt})$ & 12.74 & 11.34 & 9.61 & $1.5-5.8$ \\
\hline Lower heating value $(\mathrm{MJ} / \mathrm{m} 3)$ & 26.24 & 23.15 & 19.35 & 36.0 \\
\hline Cetane number & & & & 59.8 \\
\hline Octane number & $>130$ & $>130$ & $>130$ & \\
\hline
\end{tabular}

\section{RESULTS}

The results of the emission mannerism of the engine for diesel as direct-injected test fuel with the biogas as port-induced fuel are discussed in this section.

\section{A. Combustion Process Characterization}

Examination of the stages of in-cylinder temperature generation is pertinent for a proper understanding of the fundamentals of burning biogas/diesel in dual-fuel RCCI mode. Analysis of the temperature progression in Fig 2a revealed that the attainment of the diesel autoignition temperature occurred around $6-10^{\circ} \mathrm{CA}$ BTDC depending on the $\mathrm{CO}_{2}$ ratio. Biogas with $45 \% \mathrm{CO}_{2}$ indicated the highest temperature produced up to the top dead center (TDC), implying that it might result in less ignition delay. Attaining the diesel autoignition temperature before the end of compression is a piece of evidence that ignition was initiated in some reactivity pockets but did not cause fire of the whole mixture. Subsequently, substantial growth in the temperature happened immediately after the TDC up to around $10^{\circ} \mathrm{CA}$ ATDC (crank angle after top dead center), reaching a critical temperature of 1000 to $1100 \mathrm{~K}$, which is within the range of biogas autoignition temperature. At this temperature range, the second staged ignition occurred and ignited the whole mixture. These characteristics are similarly observed in Fig $2 \mathrm{~b}, 2 \mathrm{c}$, and 2d. At around $10-20^{\circ} \mathrm{CA}$ ATDC, the presence of high $\mathrm{CO}_{2}$ inhibits the combustion and slows down the ignition, thereby reducing the flame temperature and the rate of increase in temperature. As observed from Fig 2a, the rate of temperature generation drastically reduced with the use of $45 \% \mathrm{CO}_{2}$ compared to the rest of the $\mathrm{CO}_{2}$ ratios, though $35 \% \mathrm{CO}_{2}$ demonstrated the highest peak temperature 
produced for the biogas fraction of $40 \%$. Similar trends occurred at the higher fractions, as depicted in Fig $2 \mathrm{~d}$ for a fraction of $70 \%$. The decrement in the temperature could be an attribute of the radiation absorption effect of elevated $\mathrm{CO}_{2}$ concentration resulting in significant energy absorption from the reaction due to its high specific heat. The case of $25 \% \mathrm{CO}_{2}$ having a lower temperature compared to $35 \% \mathrm{CO}_{2}$ at the peak of the combustion might relate to the change in thermal diffusivity in the flame relative to $35 \% \mathrm{CO}_{2}$.
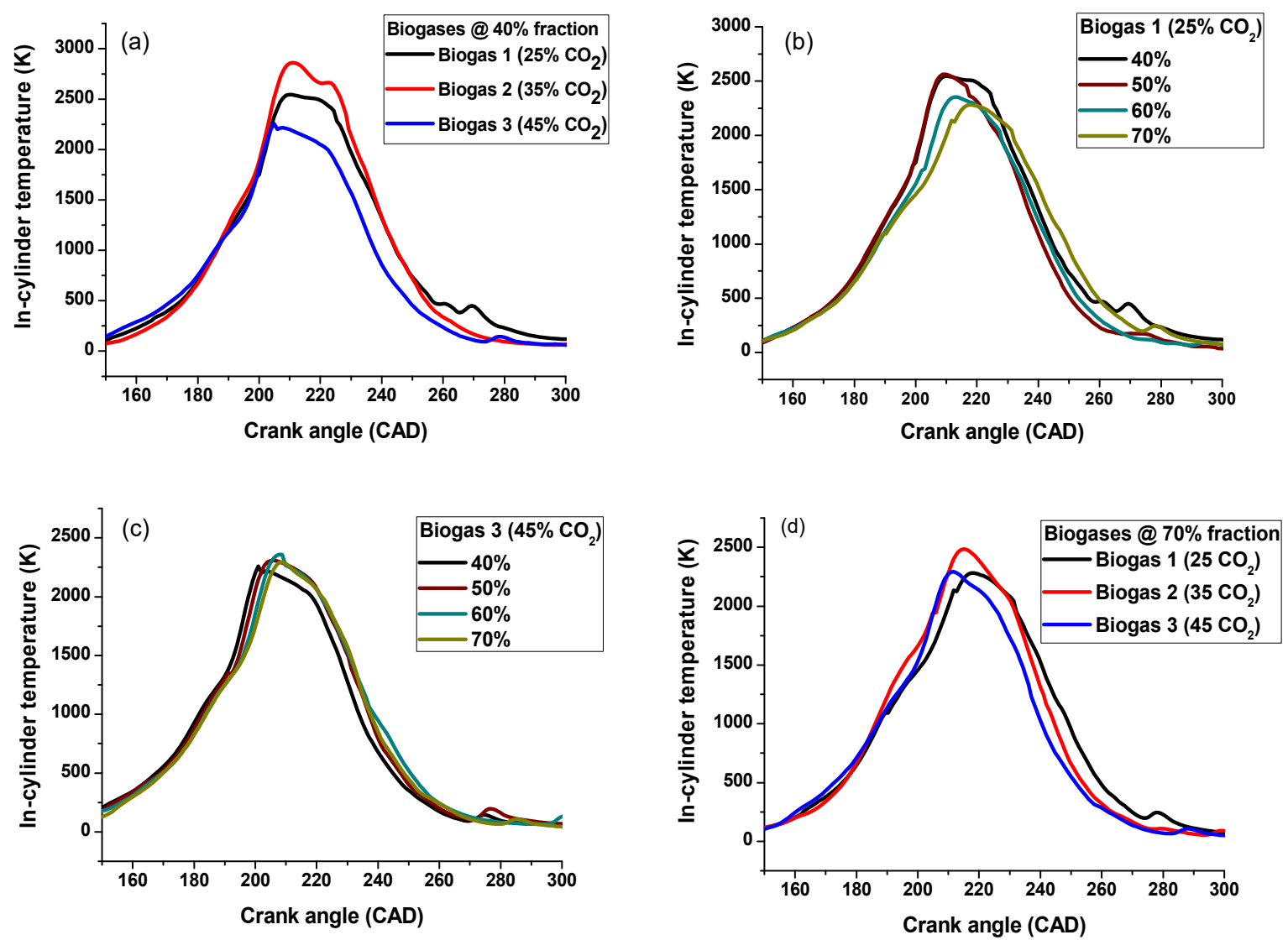

Fig. 2. In-cylinder temperature traces for; (a) a 40\% fraction and various biogases; (b) various fractions of biogas 1 ; (c) various fractions of biogas 3 ; and (d) a $70 \%$ fraction and various biogases

To examine the attributes of the reactivity of the fuel relative to the temperature produced, Fig $2 \mathrm{~b}$ presents the trends of the temperature developed for the various fractions of biogas $1\left(25 \% \mathrm{CO}_{2}\right)$. An increase in the biogas fraction resulted in a decreased maximum temperature in the cylinder, which is contrary to the trend of biogas 3 $\left(45 \% \mathrm{CO}_{2}\right)$ shown in Fig $2 \mathrm{c}$. These variabilities might attribute to the combined effects of mixture reactivity formation, radiation absorption, along with hydrogen and methyl radical's oxidation. Besides the cylinder temperature, high $\mathrm{CO}_{2}$ content and biogas fraction also affect other combustion indicators. Therefore, Fig 3a indicated a significantly decreased pressure as biogas fraction increased for the different $\mathrm{CO}_{2}$ ratios. Thus, $70 \%$ of the biogas fraction demonstrated a pattern of maximum pressure similar to that of $40 \%$, unlike 50 and $60 \%$. At 50 and $60 \%$ fractions, $35 \% \mathrm{CO}_{2}$ showed the highest maximum pressure. Besides the change in thermal diffusivity, specific heat content, radiation absorption, and methyl radical recombination, other factors such as equivalence ratio might cause some variabilities in the pressure due to an increase in $\mathrm{CO}_{2}$ content. As observed in Fig 3b, biogas having $35 \% \mathrm{CO}_{2}$ characterized with the highest total HRR across the portion, while $45 \% \mathrm{CO}_{2}$ demonstrated the lowest ability. The trends could be due to change in the cylinder temperature. This attribute could relate to the fact that the use of $45 \% \mathrm{CO}_{2}$ might result in the production of methyl radicals that could recombine at high temperatures and inhibit the combustion; thus, lowering the cylinder temperature and, subsequently, the HRR. Similar attributes were observed at fractions of 50 to $70 \%$ biogas, with a consistent pattern. 


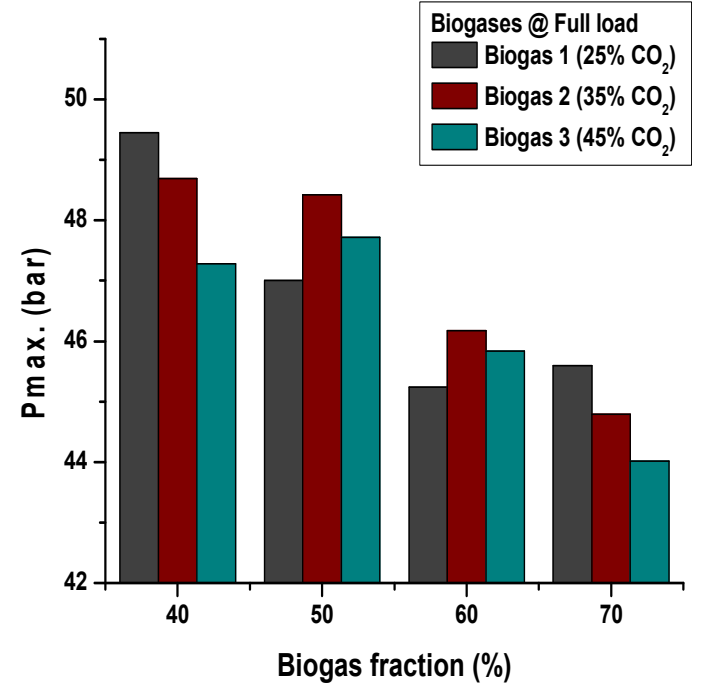

(a)

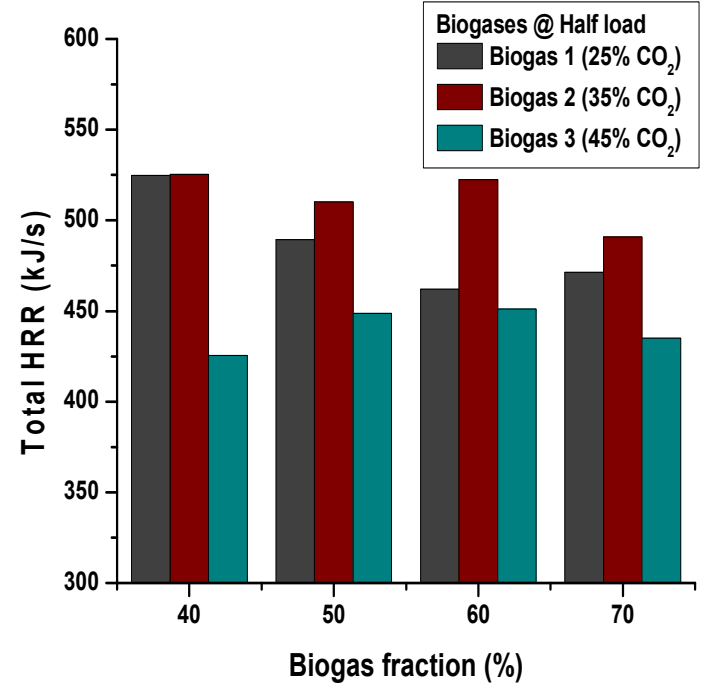

(b)

Fig. 3. (a) Pmax and (b) Total HRR at different fractions and $\mathrm{CO}_{2}$ contents for Diesel-Biogas at full capacity

1) Effects of high $\mathrm{CO}_{2}$ and biogas fraction on the peak pressure rise rate: Another critical aspect of cylinder condition is the average rate at which the pressure gets elevated per unit crank angle. The frequency at which the pressure gets elevated has no definite pattern with increased biogas fraction for all the $\mathrm{CO}_{2}$ ratios, as shown in Fig 4. Likewise, the rate of peak pressure rises does not adopt any specific model, relative to $\mathrm{CO}_{2}$ growth, at all the fraction. A trend of fall and rise in PPRR, relative to increased $\mathrm{CO}_{2}$ portion, manifested at fractions of 40 and $70 \%$ biogas for the full capacity with the occurrence of counter rule at $50 \%$. A trend of decrease happened at only a $60 \%$ fraction when operated at full load. The differences might attribute to variability in mixture homogeneity due to advanced injection timing [22]. However, these patterns signify that neither increase in the $\mathrm{CO}_{2}$ proportion nor that of biogas fraction has a significant influence on the PPRR; hence, the parameters might not influence an increase in the ringing intensity. According to [23], a high amount of direct-injected fuel influences reduced ringing intensity; thus, affecting the PPRR at some conditions.

Generally, the values of the PPRR fall within the range of $1.5-1.8 \mathrm{bar} / \mathrm{CA}$ at half load, and $1.5-1.7 \mathrm{bar} / \mathrm{CA}$ at full capacity for all the $\mathrm{CO}_{2}$ proportions and biogas fractions. Therefore, the rate is considered generally low, in fact, much lower than the $4 \mathrm{bar} / \mathrm{CA}$ as the EURO VI limit for the light-duty diesel engine. Unlike the effects of the increased $\mathrm{CO}_{2}$ ratio and biogas fraction, the use of high $\mathrm{CO}_{2}$ proportion could suppress the ringing intensity and extend the operational range of the RCCI engine because of the radiation absorption effect of $\mathrm{CO}_{2}$, which improves the lean burn limit of biogas [24]. Given this perspective is a piece of evidence that the use of diesel and biogas with high $\mathrm{CO}_{2}$ proportion in RCCI can extend the engine load to a more upper limit.

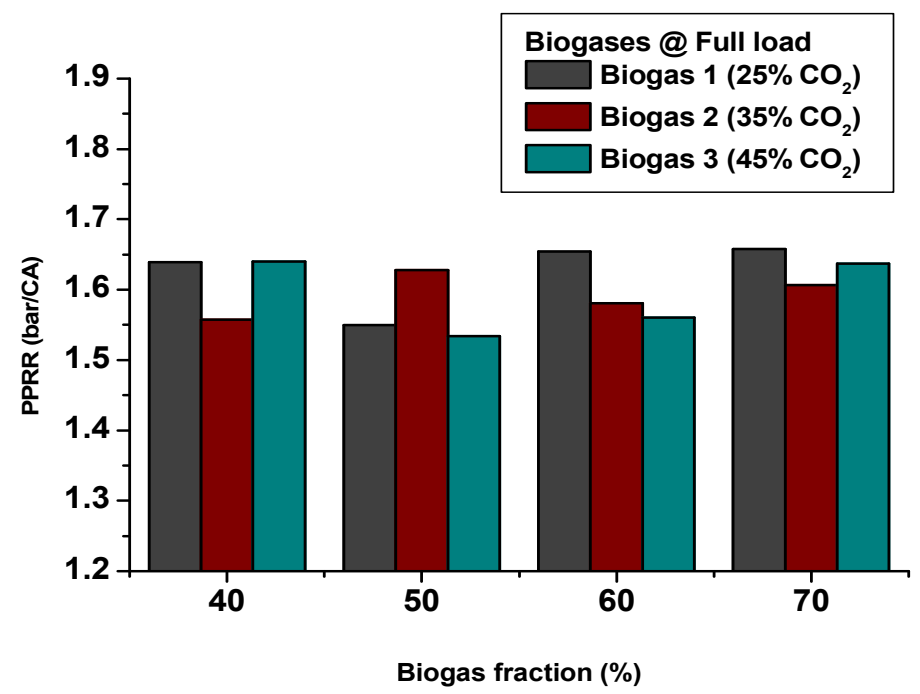

Fig. 4. PPRR at different fractions and $\mathrm{CO}_{2}$ contents for Diesel-Biogas at full load 


\section{B. Effects of high $\mathrm{CO} 2$ and biogas fraction on the performance attributes}

Indicated thermal efficiency (ITE) and brake specific fuel consumption (BSFC) were examined as the performance indicators to complement the studies. The engine efficiency during diesel-biogas combustion decreases with the increased biogas fraction for all the $\mathrm{CO}_{2}$ portions, which is depicted in Fig 5a. The decrement might relate to reduced indicated power as the biogas fraction increases, which affected the net energy produced. The highest ITE achieved was $38.29 \%$ at a $40 \%$ biogas fraction and $25 \% \mathrm{CO}_{2}$, as a consequence of more concentration of combustible compound generating higher heat as established in Fig $3 \mathrm{~b}$. Other reasons could be fewer heat losses through the cylinder wall at this particular condition. The ITE decreased as the $\mathrm{CO}_{2}$ content increases at a biogas fraction of $40 \%$, closely similar to the outcome of $70 \%$. The decrement might also relate to reduced indicated power as the radiation absorption effect increases. A contrary trend occurred at 50 and $60 \%$ fractions, possibly because of the influence of other extraneous factors. The pattern implied that a $45 \% \mathrm{CO}_{2}$ ratio resulted in higher ITE at those fractions. The specific amount of fuel consumed increased dramatically as the fraction increases for all the $\mathrm{CO}_{2}$ rates used, as shown in Fig 5b. Increasing the fraction might result in some power losses leading to more fuel consumed, which opposed the trend of the ITE, as established in Fig 5a. Mixing 35\% $\mathrm{CO}_{2}$ causes more fuel consumption at a $40 \%$ biogas fraction and shows otherwise at other fractions. The trend of fuel consumption for the various $\mathrm{CO}_{2}$ portions might relate to fuel stratification formed, as affected by the mixing. The lowest $7.41 \mathrm{~g} / \mathrm{kWh}$ BSFC was achieved at a $40 \%$ biogas fraction and $25 \% \mathrm{CO}_{2}$ that simultaneously indicated the highest ITE. It signifies that operating the engine with a low fraction of biogas having low $\mathrm{CO}_{2}$ content looks more economical.

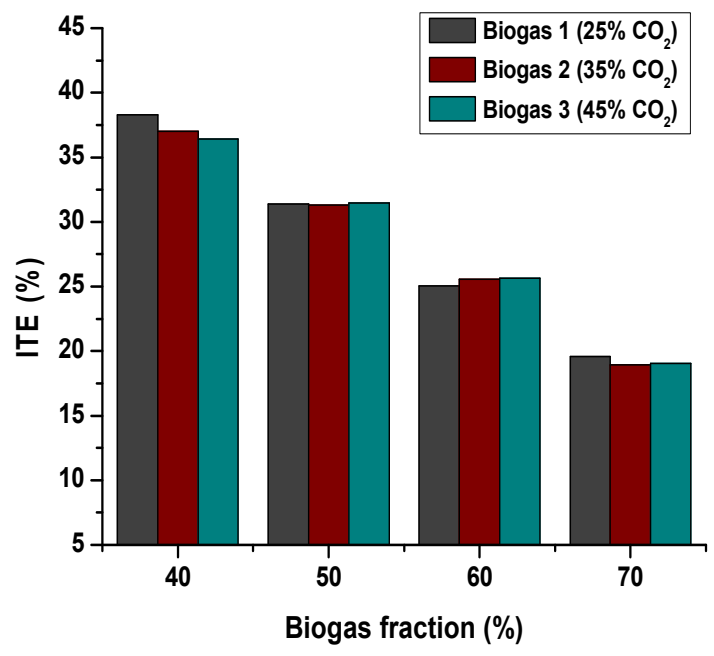

(a)

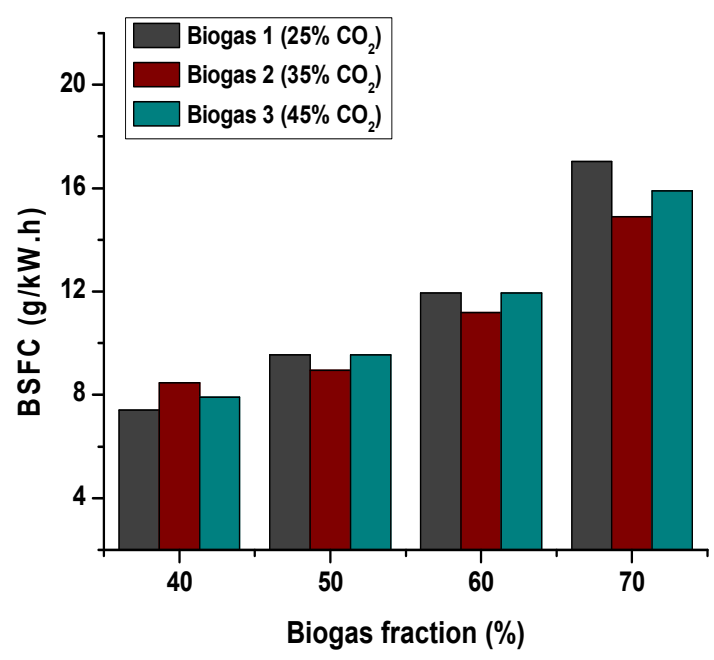

(b)

Fig. 5. (a) Variation of (a) ITE and (b) BSFC for diesel-biogas at different $\mathrm{CO}_{2}$ ratios and biogas fractions in RCCI combustion

\section{Exhaust Discharge Attributes}

Various emission parameters were studied to examine the influence of the $\mathrm{CO}_{2}$ contents and fuel fractions on the discharge characteristics of biogas/diesel dual-fuel RCCI engine at full load.

1) Oxides of Carbon Emissions: The carbon dioxide $\left(\mathrm{CO}_{2}\right)$ emission is among the essential emission parameters of this study because of its varied concentration in the biogas used. As shown in Fig 6a, the $\mathrm{CO}_{2}$ emission increased with the increase in the biogas fraction for all the diluent contents. Increasing biogas fraction to $50 \%$ causes a gradually increased $\mathrm{CO}_{2}$ emission for all the diluent contents. As the biogas fraction rises to $70 \%$, substantial $\mathrm{CO}_{2}$ was emitted due to elevated diluent concentration, which increases the radiation absorption effect and reduces the active involvement of the $\mathrm{CO}_{2}$ in the reactions causing higher $\mathrm{CO}_{2}$ emission. At 40 and $50 \%$ fractions, a trend of rising and fall in the $\mathrm{CO}_{2}$ discharge occurred, indicating the highest emission with a $35 \%$ diluent content. The higher $\mathrm{CO}_{2}$ emission at a diluent range of $45 \%$ could attribute to more oxidation of $\mathrm{CO}$ to $\mathrm{CO}_{2}$, which increases the rate of $\mathrm{CO}_{2}$ emissions. In contrast, a trend of increased $\mathrm{CO}_{2}$ emission due to increased diluent content manifested for 60 and $70 \%$ fractions, likely because the cooling effects of high diluent content at these fractions counteracted the $\mathrm{CO}$ oxidation effects due to raised temperature. Increasing biogas fraction from 40 to $70 \%$ resulted in an increased $\mathrm{CO}_{2}$ emission by $38.62,35.88$, and $46.65 \%$ for biogases 1,2 , and 3 , respectively. 
Fig $6 \mathrm{~b}$ shows that the carbon monoxide (CO) emission increased with the increase in the biogas fraction for all the diluent $\mathrm{CO}_{2}$ ratios. The use of $25 \%$ diluent $\mathrm{CO}_{2}$ indicated a gradual increased $\mathrm{CO}$ emission as the biogas fraction increased from 40 to $60 \%$ and fell at a fraction of $70 \%$. In contrast, the steepest trend appeared with the use of 35 and $45 \% \mathrm{CO}_{2}$ ratios, indicating a high rate of the $\mathrm{CO}$ emissions as the fraction increases. The increase in the $\mathrm{CO}$ emission as the biogas fraction increases could be an influence of hydrogen and methyl radical's oxidation under a lean condition in the presence of a high diluent ratio, which resulted in more of the $\mathrm{CO}$ and NOx formation [25]. According to Fig 2b, an increase in the fraction of biogas 1 causes a relative decrease in the peak cylinder temperature; thus, reducing the impact of $\mathrm{CO}$ emission due to hydrogen and methyl radical's oxidation. Besides, Fig $2 \mathrm{c}$ indicated a trend of increased cylinder temperature, which favored significantly increased $\mathrm{CO}$ emission for $45 \% \mathrm{CO}_{2}$, similar to $35 \%$, unlike 25\%, shown in Fig $6 \mathrm{~b}$. At a biogas fraction of $40 \%$, the $\mathrm{CO}$ emission decreased with the increase in diluent $\mathrm{CO}_{2}$ content, as similarly observed at 50 and $60 \%$. The decrease in the $\mathrm{CO}$ emission in the presence of high $\mathrm{CO}_{2}$ could be due to the recombination of the oxidized methyl radicals at the high-temperature regime [25]. Although, Fig 2a shows that Biogas 3 has the least maximum cylinder temperature and emitted less CO compared to Biogas 2, likely because of complete combustion at these fractions. Contrary to the outcome of 40,50 , and $60 \%$ fractions, the $\mathrm{CO}$ emission increased with the increase in the diluent $\mathrm{CO}_{2}$ because the influence of hydrogen and methyl radical's oxidation at high temperature was inhibited by either the cooling effect of elevated $\mathrm{CO}_{2}$ proportion or recombination of methyl radicals. Fig $2 \mathrm{~d}$ shows that the variability in the temperature might not be the reason for the $\mathrm{CO}$ emission, as biogas 2 indicated the highest peak temperature. Increasing biogas fraction from 40 to $70 \%$ resulted in an increased $\mathrm{CO}$ emission by $8.33,12.96$, and $42.31 \%$ for biogases 1,2 , and 3 , respectively. Also, increasing $\mathrm{CO}_{2}$ content from 25 to $45 \%$ decreases the CO emission by $30.82,21.74$, and $8.33 \%$ for a fraction of 40,50 , and $60 \%$, respectively. Contrarily, the $\mathrm{CO}$ emission increased by $11.54 \%$ for a biogas fraction of $70 \%$.

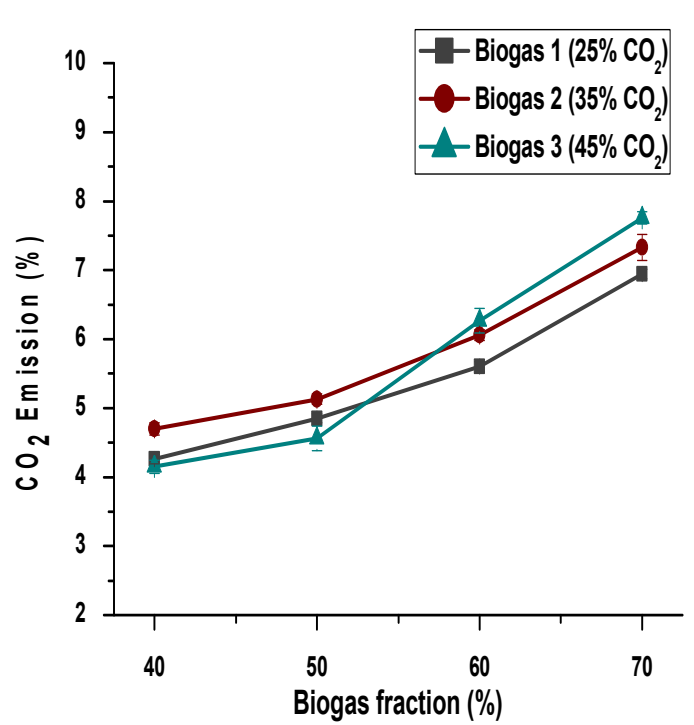

(a)

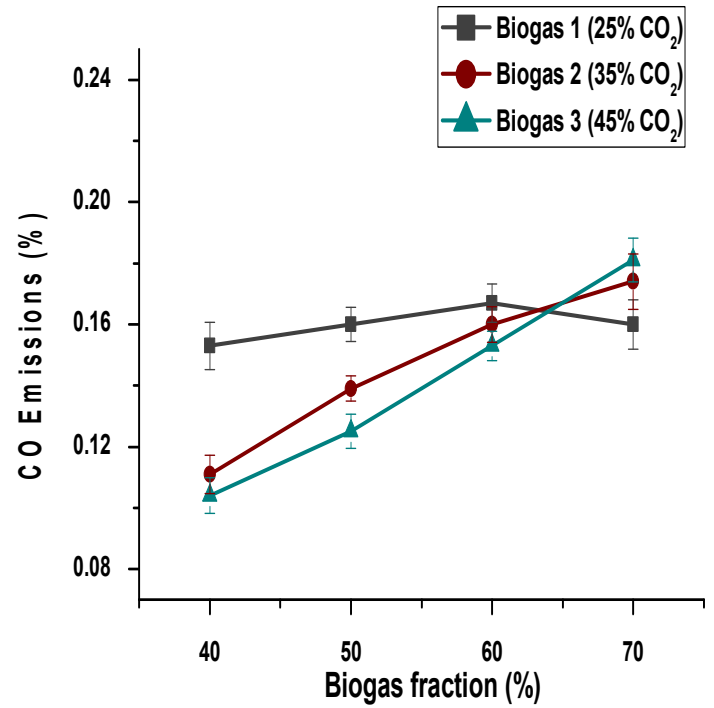

(b)

Fig. 6: (a) $\mathrm{CO}_{2}$ emission and (b) $\mathrm{CO}$ emission for the biogas-diesel in RCCI combustion

2) Unburned Hydrocarbon Emission: Fig 7a shows that UHC emission increased with the increase in biogas fraction for all the diluent $\mathrm{CO}_{2}$ ratios. Increased biogas fraction indicated an increased combustible $\mathrm{CH}_{4}$, which added more of the hydrocarbon compound that needs to be burned. Also improved is the quantity of noncombustible $\mathrm{CO}_{2}$ in the mixture, which inhibits the combustion, as discussed in Section 3.1 above. Thus, a combined influence of increased combustible compounds and increased inhibition effect of high $\mathrm{CO}_{2}$ content resulted in more of the UHC emission as the biogas fraction increases. Another reason could either be an influence of reduced in-cylinder temperature, which might lower the rate of the fuel burned or higher amounts of the fuel entering the crevices, which increase the UHC emission [26-28]. 


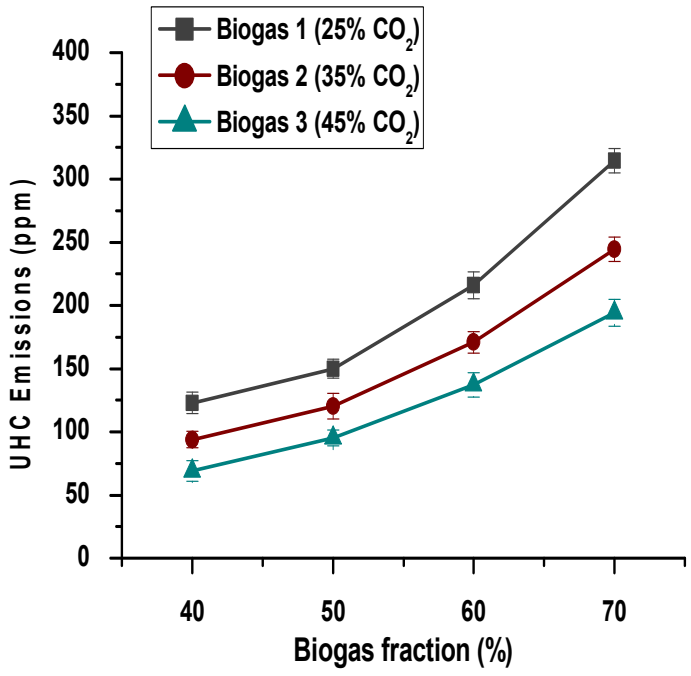

(a)

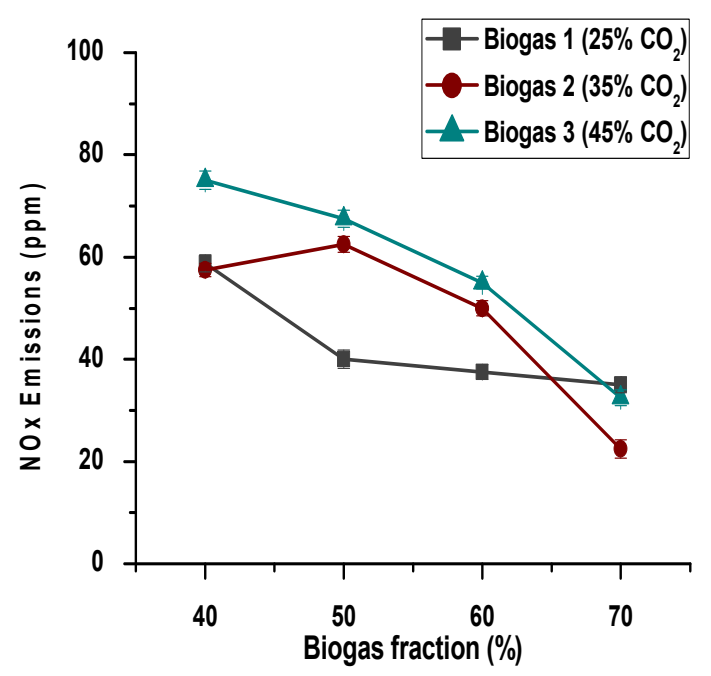

(b)

Fig. 7: (a) UHC emission and (b) NOx emission for the biogas/diesel in RCCI combustion

In contrast, the UHC emissions decreased with the increase in $\mathrm{CO}_{2}$ content for all the biogas fractions, which could be an influence of a reduced amount of explosive compounds in the mixture. Increased biogas fraction from 40 to $70 \%$ resulted in a significantly elevated UHC emission by $60.96,61.61$, and $64.48 \%$ for 25,35 , and $45 \% \mathrm{CO}_{2}$, respectively. Also, raising $\mathrm{CO}_{2}$ content to $45 \%$ decreases significantly, the UHC emission by 43.87 , $36.68,36.46$, and $38.31 \%$ for the biogas fraction of $40,50,60$, and $70 \%$, respectively.

3) Oxides of Nitrogen Emission: Analysis of NOx emission is pertinent to properly understand the extent of the emission trade-off with the use of biogas in RCCI combustion. According to Fig 7b, the NOx emission decreased with the increase in biogas fraction for all the $\mathrm{CO}_{2}$ contents, likely because of reduced cylinder temperature, which reduces the rate of nitrogen-oxygen bond formation [29]. The use of $25 \% \mathrm{CO}_{2}$ indicated a relatively different $\mathrm{NOx}$ emission trend resulting in higher emission at a biogas fraction of $70 \%$, compared to 35 and $45 \% \mathrm{CO}_{2}$ contents. This pattern was likely because of more influence of hydrogen and methyl radical's oxidation under a lean condition in the presence of a high diluent ratio at $70 \%$ fraction, which resulted in more of the NOx formation [25]. However, different rules applied to the NOx emissions due to an increase in the $\mathrm{CO}_{2}$ content at various biogas fractions, which could be due variability of the temperature trends at different ratios and $\mathrm{CO}_{2}$ ranges, as shown in Fig 2. The attribute in the temperature produced signifies that it might not be the most influential factor for the NOx emission. Still, hydrogen and methyl radical's oxidation could play a more significant role. Increase biogas fraction to $70 \%$ resulted in a decreased NOx emission by $40.43,60.87$, and $56.67 \%$ for 25,35 , and $45 \% \mathrm{CO}_{2}$, respectively. Also, raising $\mathrm{CO}_{2}$ content to $45 \%$ increase the NOx emission by $21.67,40.74$, and $31.82 \%$ for a fraction of 40,50 , and $60 \%$, respectively. Contrarily, the NOx emission decreased by $7.14 \%$ for a biogas fraction of $70 \%$. An increase in the biogas fraction resulted in a severe NOx emission trade-off with $\mathrm{UHC}$ and $\mathrm{CO}$ emission for all the $\mathrm{CO}_{2}$ contents, as shown in Fig 6b, 7a, and 7b. Besides, the exchange occurred because of high $\mathrm{CO}_{2}$ contents in various biogas fractions except for $70 \%$, which shows the tendency of mitigating the trade-off.

4) Particulate Matter (PM) Emission: Fig 8 depicted that PM emission decreased gradually as the biogas fraction increased from 40 to $60 \%$ while elevates at a fraction of $70 \%$ for all the $\mathrm{CO}_{2}$ contents. According to [30], a reduced amount of diesel with an advanced injection timing improves the fuel mixing causing a reduced soot emission. This pattern implies that there might likely an optimum mixing at a fraction of $60 \%$, resulting in less PM emission. The PM emission increased with the increase in the $\mathrm{CO}_{2}$ content for all the biogas fraction. An increase in the $\mathrm{CO}_{2}$ content inhibits the combustion, which might probably increase the rate of carbon blacks. Increasing biogas fraction from 40 to $60 \%$ resulted in a decreased PM emission by $35.29,31.37$, and $13.11 \%$ for 25,35 , and $45 \% \mathrm{CO}_{2}$, respectively. Contrarily, raising biogas fraction to $70 \%$ increased the PM emission by $38.89,30.00$, and $11.67 \%$ for 25,35 , and $45 \% \mathrm{CO}_{2}$, respectively. Also, elevating $\mathrm{CO}_{2}$ content to $45 \%$ increase the PM emission by $44.26,56.14,58.49$, and $40.00 \%$ for a fraction of $40,50,60$, and $70 \%$ respectively. An increase in the biogas fraction resulted in a serious PM emission trade-off with the UHC and CO emission for all the $\mathrm{CO}_{2}$ contents, as shown in Fig 6b, 7a, and 8. Besides, the trade-off also occurred with the increase in the $\mathrm{CO}_{2}$ contents for the various biogas fractions. 


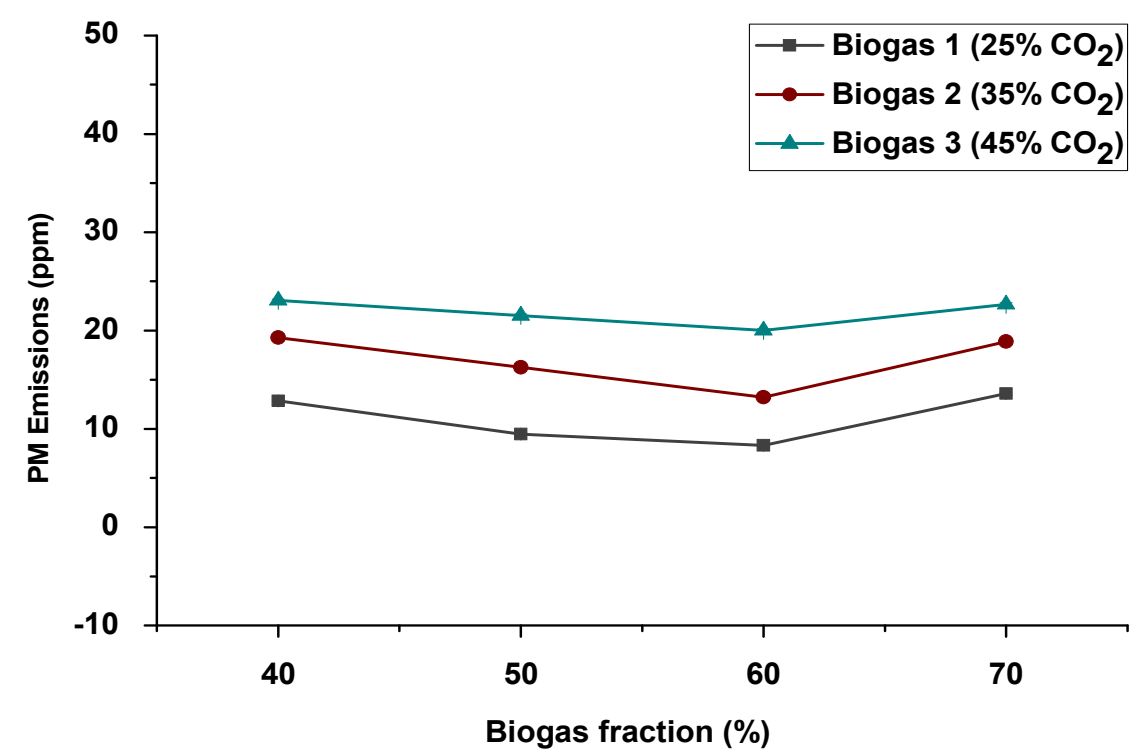

Fig. 8: PM emission for the biogas-diesel in RCCI combustion

\section{General Discussion}

The results indicated because of high radiation absorption effects that, high $\mathrm{CO}_{2}$ content in the biogas prevents the combustion. Biogas with a $\mathrm{CO}_{2}$ ratio of $35 \%$ recorded the highest maximum temperature and heat released through fractions while the highest peak temperature was registered by $50 \%$. The combustion resulted in a lower PPRR minimizing the higher-ringing strength tendency. At a $40 \%$ biogas fraction and $25 \% \mathrm{CO}_{2}$, which simultaneously showed the highest ITE, the lowest BSFC was achieved. An increase in the biogas fraction caused a raised $\mathrm{CO}$ and $\mathrm{CO}_{2}$ emissions, while different rules applied as the diluent ratio increases at various fractions. An increase in the diluent content decreases the $\mathrm{CO}$ emission at all fraction except $70 \%$, because of the increased rate of methyl radical recombination at high temperature. In contrast, an increase in the diluent ratio increases the $\mathrm{CO}_{2}$ emission at higher biogas fraction, while a Biogas 2 produced the highest emission at lower fractions. An increased rate of $\mathrm{CO}$ oxidation tends to increase the $\mathrm{CO}_{2}$ emission at the higher diluent ratio. An increased biogas fraction resulted in a significantly increased UHC emission for all the biogases due to reduced amounts of the fuel entering the crevices or the combined influence of increased combustible compounds and cooling effect of high $\mathrm{CO}_{2}$ content. In contrast, an increase in the $\mathrm{CO}_{2}$ content decreases significantly, the UHC emission for all the biogas fractions due to the reduced amount of explosive compounds in the mixture.

NOx emission decreased with the increase in biogas fraction for all the $\mathrm{CO}_{2}$ contents, because of reduced cylinder temperature. At the same time, different rules applied to the $\mathrm{NOx}$ emissions as the $\mathrm{CO}_{2}$ content increases at various biogas fractions because of the influence of hydrogen and methyl radical's oxidation at high temperatures. Similarly, $\mathrm{PM}$ emission decreased with the increase in biogas fraction for all the $\mathrm{CO}_{2}$ contents while increase with the increase in $\mathrm{CO}_{2}$ content at various fractions. Both NOx and PM emissions indicated a trade-off with $\mathrm{UHC}$ and $\mathrm{CO}$ emissions at different $\mathrm{CO}_{2}$ ranges and biogas fractions except $70 \%$, which shows the potentiality of reducing the compromise.

\section{Conclusion}

An experimental investigation was carried out to examine the influence of high $\mathrm{CO}_{2}$ contents and fractions of biogas in RCCI combustion fueled with diesel as direct-injected fuel. The results indicated that elevated $\mathrm{CO}_{2}$ content in the biogas inhibits combustion due to high radiation absorption effects. Biogas with $35 \% \mathrm{CO}_{2}$ proportion registered the highest maximum temperature and heat released across the fractions, while $50 \%$ indicated the highest peak temperature. The combustion resulted in a significantly lower PPRR mitigating the tendency of higher ringing intensity. The lowest $7.41 \mathrm{~g} / \mathrm{kWh}$ BSFC was achieved at a $40 \%$ biogas fraction and $25 \% \mathrm{CO}_{2}$ that simultaneously indicated the highest $38.29 \%$ ITE. It signifies that operating the engine with a low fraction of biogas having low $\mathrm{CO}_{2}$ content looks more economical. An increase in the biogas fraction showed a significant increase in $\mathrm{CO}_{2}, \mathrm{CO}$, and $\mathrm{UHC}$ emissions on average by $40.38,21.20$, and $62.35 \%$, respectively. In contrast, an increase in the biogas fraction indicated a significant decrease in the NOx and PM emissions on average by 62.66 , and $26.59 \%$, respectively. Besides, an increase in the diluent $\mathrm{CO}_{2}$ content decreases the $\mathrm{CO}$ and UHC emissions on average by 20.30 and $38.83 \%$, respectively. 
In contrast, an increase in the diluent $\mathrm{CO}_{2}$ content increase the NOx and PM emissions on average by 31.41, and $49.72 \%$, respectively. Therefore, an increase in the biogas intake parameters resulted in a severe UHC and CO emissions trade-off with the NOx and PM emissions. However, $70 \%$ of biogas indicated the potentials of reducing the extent of the compromise. The use of appropriate technique along with moderate biogas fraction of $50 \%$ and $35 \% \mathrm{CO}_{2}$ content may reduce the emissions trade-off.

\section{ACKNOWLEDGMENT}

The authors would like to acknowledge the support given by the Universiti Teknologi Petronas (UTP) and Centre for Automotive Research and Electric Mobility (CAREM) in conducting this research.

\section{REFERENCES}

[1] S. E. Hosseini and M. A. Wahid, "Biogas utilization: Experimental investigation on biogas flameless combustion in the lab-scale furnace," Energy Convers. Manag., vol. 74, pp. 426-432, 2013.

[2] C. A. Cardona and A. A. Amell, "Laminar burning velocity and interchangeability analysis of biogas/C 3H8/H2 with normal and oxygen-enriched air,” Int. J. Hydrogen Energy, vol. 38, no. 19, pp. 7994-8001, 2013.

[3] Y. Wang, Z. Zhu, M. Yao, T. Li, W. Zhang, and Z. Zheng, "An investigation into the RCCI engine operation under low load and its achievable operational range at different engine speeds," Energy Convers. Manag., vol. 124, pp. 399-413, 2016.

[4] J. Li, W. Yang, and D. Zhou, "Review on the management of RCCI engines," Renew. Sustain. Energy Rev., vol. 69, no. May 2016, pp. 65-79, 2017.

[5] Firmansyah, A. A. Aziz, M. Heikal, and E. Zainal A., "Diesel/CNG Mixture Autoignition Control Using Fuel Composition and Injection Gap,” Energies, vol. 10, no. 10, p. 1639, 2017.

[6] Y. Li, H. Li, H. Guo, Y. Li, and M. Yao, "A numerical investigation on methane combustion and emissions from a natural gas-diesel dual-fuel engine using CFD model," vol. 205, no. August, pp. 153-162, 2017.

[7] B. J. Bora and U. K. Saha, "Optimization of injection timing and a compression ratio of a raw biogas powered dual-fuel diesel engine," Appl. Therm. Eng., vol. 92, pp. 111-121, 2016.

[8] F. Z. Aklouche, K. Loubar, A. Bentebbiche, S. Awad, and M. Tazerout, "Experimental investigation of the equivalence ratio influence on combustion, performance and exhaust emissions of a dual fuel diesel engine operating on synthetic biogas fuel," Energy Convers. Manag., vol. 152, no. August, pp. 291-299, 2017.

[9] Y. Qian, S. Sun, D. Ju, X. Shan, and X. Lu, "Review of the state-of-the-art of biogas combustion mechanisms and applications in internal combustion engines," Renew. Sustain. Energy Rev., vol. 69, no. November 2016, pp. 50-58, 2017.

[10] B. J. Bora, U. K. Saha, S. Chatterjee, and V. Veer, "Effect of compression ratio on performance, combustion and emission characteristics of a dual fuel diesel engine run on raw biogas," Energy Convers. Manag., vol. 87, pp. 1000-1009, 2014.

[11] B. J. Bora and U. K. Saha, "Experimental evaluation of a rice bran biodiesel e biogas run dual fuel diesel engine at varying compression ratios," Renew. Energy, vol. 87, pp. 782-790, 2016.

[12] O. Mathieu, M. M. Kopp, and E. L. Petersen, "Shock-tube study of the ignition of multi-component syngas mixtures with and without ammonia impurities," Proc. Combust. Inst., vol. 34, no. 2, pp. 3211-3218, 2013.

[13] X. Wang, Y. Qian, Q. Zhou, and X. Lu, "Modulated diesel fuel injection strategy for efficient-clean utilization of low-grade biogas," Appl. Therm. Eng., vol. 107, pp. 844-852, 2016.

[14] Y. Qian, Y. Zhang, X. Wang, and X. Lu, "Particulate matter emission characteristics of a reactivity controlled compression ignition engine fueled with biogas/diesel dual fuel," J. Aerosol Sci., vol. 113, no. August, pp. 166-177, 2017.

[15] X. Shan, Y. Qian, L. Zhu, and X. Lu, "Effects of EGR rate and hydrogen/carbon monoxide ratio on combustion and emission characteristics of biogas/diesel dual-fuel combustion engine," Fuel, vol. 181, pp. 1050-1057, 2016.

[16] M. Ebrahimi and S. A. Jazayeri, "Effect of hydrogen addition on RCCI combustion of a heavy-duty diesel engine fueled with landfill gas and diesel oil," Int. J. Hydrogen Energy, vol. 44, no. 14, pp. 7607-7615, 2019.

[17] I. B. Dalha, M. A. Said, and S. E. M. Karim, Zainal A Abdul, "An Experimental Investigation on the Influence of Port Injection at Valve on Combustion and Emission Characteristics of B5 / Biogas RCCI Engine," Appl. Sci., vol. 10, no. 452, pp. 1-25, 2020.

[18] Y. Wang, M. Yao, T. Li, W. Zhang, and Z. Zheng, "A parametric study for enabling reactivity controlled compression ignition (RCCI) operation in diesel engines at various engine loads," Appl. Energy, vol. 175, pp. 389-402, 2016.

[19] C. Kavuri, J. Paz, and S. L. Kokjohn, "A comparison of Reactivity Controlled Compression Ignition (RCCI) and Gasoline Compression Ignition (GCI) strategies at high load, low-speed conditions," Energy Convers. Manag., vol. 127, pp. 324-341, 2016.

[20] A. Gharehghani, R. Hosseini, M. Mirsalim, and S. A. Jazayeri, "An experimental study on reactivity controlled compression ignition engine fueled with biodiesel/natural gas," Energy, vol. 89, pp. 558-567, 2015.

[21] I. Bortel, M. Takáts, and M. Diviš, "Emissions and performance of diesel - natural gas dual-fuel engine operated with stoichiometric mixture," vol. 208, pp. 722-733, 2017.

[22] I. B. Dalha et al., "Reactivity Controlled Compression Ignition: An Advanced Combustion Mode for Improved Energy Efficiency," in Energy Efficiency in Mobility Systems, Springer, 2020, pp. 101-126.

[23] J. Du, X. Chen, L. Liu, D. Liu, and X. Ma, "Mechanism of combustion noise influenced by pilot injection in PPCI diesel engines," Appl. Sci., vol. 9, no. 9, 2019.

[24] L. Pizzuti, C. A. Martins, and P. T. Lacava, "Laminar burning velocity and flammability limits in biogas : A literature review," Renew. Sustain. Energy Rev., vol. 62, pp. 856-865, 2016.

[25] M. Fischer and X. Jiang, "An investigation of the chemical kinetics of biogas combustion," Fuel, vol. 150, pp. 711-720, 2015.

[26] S. Imtenan et al., "Impact of low-temperature combustion attaining strategies on diesel engine emissions for diesel and biodiesels : A review," Energy Convers. Manag., vol. 80, no. x, pp. 329-356, 2014.

[27] J. H. Lim and R. D. Reitz, "High Load (21 Bar IMEP) Dual Fuel RCCI Combustion Using Dual Direct Injection," J. Eng. Gas Turbines Power, vol. 136, no. 10, p. 101514, 2014.

[28] M. Wissink and R. D. Reitz, "Direct dual fuel stratification, a path to combine the benefits of RCCI and PPC," SAE Int. J. Engines, vol. 8, no. 2, pp. 2015-01-0856, 2015.

[29] Isik Z. M. and A. Hüseyin, "Analysis of ethanol RCCI application with safflower biodiesel blends in a high load diesel power generator," Fuel, vol. 184, pp. 248-260, 2016.

[30] J. Benajes, A. García, J. Monsalve-Serrano, and R. Lago Sari, "Fuel consumption and engine-out emissions estimations of a light-duty engine running in dual-mode RCCI/CDC with different fuels and driving cycles," Energy, vol. 157, pp. 19-30, 2018. 


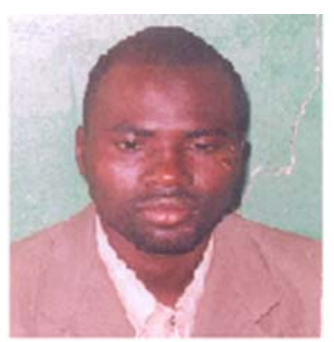

\section{AUTHOR PROFILE}

Ibrahim Babangida Dalha is a lecturer in the Department of Agricultural and Bioresources Engineering, Ahmadu Bello University, Zaria, Nigeria. He received a Master of Science in farm power and machinery engineering from Ahmadu Bello University, Zaria and currently he is a $\mathrm{PhD}$ candidate in the Department of Mechanical Engineering, Universiti Teknologi PETRONAS, Malaysia. His research interest is; Biomass combustion, Biomass energy application, Emission reduction techniques, Farm power and machinery.

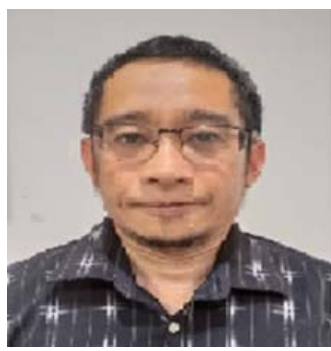

Dr Mior Azman Bin Meor Said is a Senior Lecturer in the Department of Mechanical Engineering, Universiti Teknologi PETRONAS, Malaysia. He received a $\mathrm{PhD}$ in Mechanical Engineering from University of Southern Queensland, Australia. His research interest is; Heat transfer, Energy System, Internal combustion engine, waste heat recovery about the first author of the manuscript should be updated here.

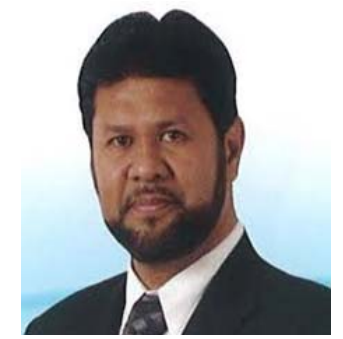

Dr Zainal Ambri bin Abdul Karim is an Associate Professor in the Department of Mechanical Engineering, Universiti Teknologi PETRONAS, Malaysia. He received a $\mathrm{PhD}$ in Mechanical Engineering from Loughborough University, United Kingdom. His research interest is; Internal Combustion Engines, Combustion diagnostics, Emissions, Energy monitoring system, Energy audit, Thermal power plant efficiency, Gas district cooling, Powertrain technology, Power plant optimization, Spray characterization and Visualization. 